\title{
The role of free iron in cardiovascular diseases - Part I
}

\author{
M Izzo ${ }^{1,4}$, V Gasbarro ${ }^{1,2}$, V Coscia ${ }^{1,3}$ \\ ${ }^{1}$ Research Center "Mathematics for Technology, Medicine and Biosciences", University of Ferrara, Via Saragat 1, \\ 44122 Ferrara \\ 2 Department of Morphology, Surgery and Experimental Medicine, University of Ferrara, Via A. Moro 8, 44124 Ferrara \\ 3 \\ 3 Department of Mathematics and Computer Science, University of Ferrara, Via Machiavelli 35, 44121 Ferrara \\ (corresponding author, email: vincenzo.coscia@unife.it) \\ ${ }^{4}$ Compression Therapy study Group (CTG)
}

submitted: May 25, 2017, accepted: Jun 18, 2017, EPub Ahead of Print: Jun 29, 2017, published: Sep 27, 2017

Conflict of interest: none

DOI: 10.24019/jtavr.23 - Corresponding author: Prof. Vincenzo Coscia, vincenzo.coscia@unife.it, cos@unife.it

(C) 2017 Fondazione Vasculab impresa sociale ONLUS. All rights reserved.

\begin{abstract}
An unavoidable consequence of the aerobic mechanism is the production of super-oxides and peroxides known as "Reactive Oxygen Species" (ROSs). These substances can trigger a number of biological reactions not particularly dangerous at physiological concentration. However, in presence of iron such reactions greatly enhance the radicals production and, in particular, determine the release of strongly reactive and toxic radicals as the hydroxyl radical $\left(\mathrm{OH}^{*}\right)$. Many chronic inflammatory conditions share this underlying disequilibrium of the iron induced radical-antiradical balance. Aim of the present review is to enlighten the role of the free or weakly chelated portion of iron in vascular and cardiac diseases.
\end{abstract}

Keywords Reactive Oxygen Species, Unchelated iron, Free Radicals, Cardiovascular diseases, Iron-mediated reactions

\section{Introduction}

The large number of works recently appeared in the literature report on the crucial role of the iron in different pathologies such as the cardiovascular diseases, the atherogenesis, the advanced dystrophic-ulcerative stages of the chronic venous disease, the diabetes mellitus, the chronic neurodegenerative illness, etc. Actually, underlying these different pathologies seem to exist a common denominator, that is the continuous iron-induced production of very toxic free radicals such as the hydroxyl radical $\left(\mathrm{OH}^{\cdot}\right)^{[1]}$. A portion of iron exists that is non effectively chelated by the physiological ligand carriers (transferrin, ferritin, albumin, lactoferrin, etc.). This iron portion is able to silently but continuously initiate a progressive and worsening biological damage, together with the decay of the biological function and of the organs. The biochemical complexity of reactions induced by the highly toxic radicals (hydroxyl, $\mathrm{OH}^{*}$, etc.) provides an explanation of the often conflicting effects of the so called "substances with antiradical activity", that from defenders become attackers when, due to different reasons, non-chelated iron is present. The hydroxyl radical $\mathrm{OH}^{-}$is normally a byproduct of water hydrolysis due to radiations or by the Fenton reaction starting from the hydrogen peroxide (with the ferrous ion $\mathrm{Fe}^{++}$as catalyst). It is the more reactive ROS and is also produced by the leukocyte starting from the hydrogen peroxide in order to destroy pathogenic agents though, in case of excess, it causes damages to the plasmatic membrane, to proteins and to nucleic acids. The hydroxyl radical is inactivated and then disposed of through conversion into $\mathrm{H}_{2} \mathrm{O}$ by glutathione peroxidase. Therefore, the chelation of iron and, possibly, of other metallic ions such as copper etc. by natural or syntetic chelant agents could play a critical role in the safeguarding of the biological functions of organ and apparatus. Understanding the mechanisms of unbound iron has a basic relevance in the differentiation of anti-phlogistic 
and pro-phlogistic processes. These "escape reactions" on which the unbound iron initiate the production of the hydroxyl radical are hard to counter since they work at the same time on different biological targets. Some molecules (statins, erythropoietin, etc.), usually not associated to antiphlogistic effects, actually reveal useful to fight such mechanisms. The role of scarcely chelated iron is pretty underestimated while it could help in the understanding of the different oxidative reactions creating a chronic biological damage and could permit the tuning of new therapeutic strategies.

\section{Iron-related physiological processes}

In the respiratory chain, during the conversion of oxygen in respiratory water a variable portion of reduced oxygen (about $2-4 \%$ ) is produced in the form of hydrogen peroxide and superoxide $\left(\mathrm{H}_{2} \mathrm{O}_{2}, \mathrm{O}_{2}^{-\cdot}\right)$, the superoxide dismutases (SOD) and the catalase (CAT) control the process $^{1,2}$ :

$$
\mathrm{O}_{2}+4 \mathrm{H}^{+}+4 \mathrm{e}^{-}<-->2 \mathrm{H}_{2} \mathrm{O}
$$

Of course these redox reactions are implemented during hypoxia, ischemia or perfusion, due to the lack of the terminal electrons acceptor (oxygen). Similarly, the production of reduced forms of $\mathrm{O}_{2}$ can also be realized in vivo by means of the direct action of different enzymes such as oxygenase, oxidase and peroxidase. For example, in ischemia-perfusion conditions, the activation of the xanthine-oxidase occurs as consequence of the accumulation of calcium in the cytosol that, in turn, initiates a number of Ca-dependent enzymatic activities (phospholipase, protease, endonuclease, etc.) like the calpain, a protease that irreversibly cuts the xanthinedehydrogenase and trasforming it into the xanthine-oxidase isoform. This latter, then, oxidise the hypoxanthine to uric acid using oxygen as substrate and producing superoxide anion and hydrogen peroxide $\left(\mathrm{O}_{2}{ }^{-\cdot}, \mathrm{H}_{2} \mathrm{O}_{2}\right)$, source of oxidative stress ${ }^{3,4}$. Though cell has many antioxidative mechanisms, these oxygen species play a major role, as they are very reactive and are able to react with other species generating a cascade of other toxic radicals such as hydroxyl radicals ${ }^{5-7}$. The reactions with those particular "metallic ligands" like iron received less attention than the general role of ROS "(Reactive Oxigen Specie) ${ }^{8,9}$. They are common to many biological functions and, once set off, these reactions can lead to progressive functions alterations and eventually to diseases, in particular to progressive chronic degenerative forms.

Superoxide $\left(\mathrm{O}_{2}^{-}\right)$and peroxide $\left(\mathrm{H}_{2} \mathrm{O}_{2}\right)$ are incomplete reduction forms of oxygen. The reaction catalyzed by SOD equilibrates superoxide and peroxide ${ }^{10}$ :

$$
2 \mathrm{O}_{2} 2^{--}+2 \mathrm{H}^{+}-->\mathrm{H}_{2} \mathrm{O}_{2}+\mathrm{O}_{2}
$$

while the catalysis determines:

$$
\mathrm{H}_{2} \mathrm{O}_{2}-->\mathrm{H}_{2} \mathrm{O}+1 / 2 \mathrm{O}_{2}
$$

The most relevant reaction of hydrogen peroxide with $\mathrm{Fe}^{++}$is known as Fenton reaction. It leads to the formation of highly toxic hydroxyl radicals $\left(\mathrm{OH}^{\cdot}\right)$ :

$$
\mathrm{Fe}^{++}+\mathrm{H}_{2} \mathrm{O}_{2}-->\mathrm{Fe}^{+++}+\mathrm{OH}^{-}+\mathrm{OH}^{\cdot}
$$

Superoxide $\left(\mathrm{O}_{2}^{-}\right)$can also react with $\mathrm{Fe}^{+++}$by the Haber-Weiss reaction to produce $\mathrm{Fe}^{++}$and leading, in this way, to a redox cycle:

$$
\mathrm{O}_{2}{ }^{--}+\mathrm{Fe}^{+++}-->\mathrm{O}_{2}+\mathrm{Fe}^{++}
$$

In the same way as they work with hydrogen peroxide, radical reaction can also develop with lipidic hyperoxide $(\mathrm{ROOH})$. By means of the O-O bond rupture, alkoxy groups ( $\mathrm{RO}^{*}$ ) are produced, that are the initiators of lipidic peroxidation while, interacting with polyunsaturates fats, they form the peroxyl groups ROO; that are the actual chain amplifiers of the lipidic peroxidation ${ }^{11}$. The oxidative stress leads to considerable damages to $\mathrm{DNA}^{12}$ and to the proteins ${ }^{13,14}$ or carbohydrates denaturing, with the formation of unsoluble structures known as lipofuscins ${ }^{15}$. The action of non-bioavailable, that is, poorly chelated iron, that on the other hand works as oxidative reactions catalyst, is an often underestimated aspect in biology, For this reason it is possible to observe a situation in which there is, at the same time, iron-deficiency anaemia together with a great abundance of unbound iron acting as catalyst of oxidative reactions. Moreover the unchelated, and then biologically unavailable, iron is able to initiate, interacting with nitrogen, a nitrogen oxidative stress with formation of phlogistic carriers such as nitrogen peroxides (reaction of NO with superoxide) ${ }^{16}$ or S-nitrosothiols ${ }^{17}$. In the hemoglobin the $\mathrm{Fe}^{+++}$ferric ion binds the oxygen giving rise to $\mathrm{Fe}^{++}$ferrous ion. This oxidation takes place in the lungs, then the ferrous ion reduces again to ferric ion $\mathrm{Fe}^{++}$releasing $\mathrm{O}_{2}$. This oxidation-reduction reaction occurs both for the weakness of the bound and for the presence of $\mathrm{CO} 2$ in tissues, that reduces the affinity among hemoglobin and $\mathrm{O}_{2}$ ( $\mathrm{pH}$ variation). The reaction of ferrous iron $\mathrm{Fe}^{++}$with the oxygen in natural aerobiotic conditions produces ferric $\mathrm{Fe}^{+++}$that is less soluble and toxic, for in their evolution bacteria and fungi overcame the problem creating siderophores, which are able to capture ferric $\mathrm{Fe}^{+}$ ${ }^{++}$ions and make it available to enter intgo the plasmatic 
membrane ${ }^{18}$. The Siderophores possess such a hexatoothed chelation structure (the deferoxamine, that is produced by the Streptomyces pilosus and is highly specific to $\mathrm{Fe}^{++}$ ${ }^{+}$) and then are able to use ferric iron, of fundamental importance for growth and virulence of these bacteries ${ }^{19,20}$. More than 500 different types of microbic siderophores have been described. On the other hand, they have not been found in humans; however, as pointed out by Kaplan ${ }^{21}$, the presence of siderophores in mammals improved our knowledge of human ferrokinetics.

The discovery in 2000 of hepcidin ${ }^{22}$, an hormone produced by the liver, marked a major turning point in the understanding of the tissues ferric release and overload mechanisms as well as its role in the phlogistic processes. In fact, hepcidin is overexpressed in inflammation and has a role in the instability of atherosclerotic plaque, and it is considered an early marker of phlogosis ${ }^{23,24}$.

It is worth to remark another relevant discovery. The NGAL (lipocalin-2 or siderocalin) is a negative iron regulator having the function of a real siderophore whose role in renal diseases has been observed much earlier than creatinine $^{25}$. The lipocalins are a heterogeneous group of small ligand proteins ${ }^{26}$. It is worth to stress the correlation among lipocalins and the metalloprotease activation (MMPS), since NGALs act as allosteric activators of MMPS $^{27,28}$. A different source of oxidative stress is the erythrocyte degradation that release free hemoglobin $(\mathrm{Hb}-$ free), with endothelial damage and free iron production ${ }^{29}$, so that the formation of biliverdin in the ecchymosis absorption would have a powerful antioxidative role.

The EME-oxigenase is an enzyme in the class of oxidoreductase, that catalyzes the following reaction:

eme $+3 \mathrm{AH}_{2}+3 \mathrm{O}_{2}<-->$ biliverdine $+\mathrm{Fe}^{++}+\mathrm{CO}$ $+3 \mathrm{~A}+3 \mathrm{H}_{2} \mathrm{O}$

"A" being the A ring of the hemoglobin tetrapyrrole group, with the possibility of making available $\mathrm{Fe}^{++}$as catalyst of oxidative stress ${ }^{30}$. In physiologic conditions in a mid adult man of $70 \mathrm{Kg}$ weight, $1-2 \times 10^{8}$ red cells are destroyed per hour, corresponding to about 6.0 grams of hemoglobin per day. Since from $1 \mathrm{~g}$ of hemoglobin are derived about $35 \mathrm{mg}$ of bilirubin, this means that about 210 $\mathrm{mg}$ of bilirubin are produced per day.

\section{Cardiovascular diseases involving iron}

Arterial hypertension is considered one of the main cardiovascular risk factors, and it i known its ROS-iron mediated phlogistic genesis ${ }^{31-33}$. The ferritin rate has been correlated to the risk of developing arterial hypertension in mid adult men ${ }^{34}$ and to diabetes ${ }^{35}$. Concerning the type 2 diabetes a large number of evidences exist that stress the role of the ROS generating unbound iron in the disease onset. It is known for sure that the ROS play a role in the insuline resistance ${ }^{36-39}$. The iron excess is a proven feature of gestational diabetes ${ }^{40}$ and of the diabetes during hemochromatosis ${ }^{41}$, and the oxidative stress is involved in the mitochondrial damage and in the different diabetes complications ${ }^{42}$. Some of the anti diabetes drugs like glitazones and thiazolidinediones (pioglitazone and rosiglitazone) that improve the insuline resistance work as reducers of the iron-induced ROS production ${ }^{43,44}$. The iron could also be related, via the oxidative stress, to the level of visfatin produced by visceral adipocytes through an increase of hepcidin and the levels of lipocalin 2 (NGAL or siderocalin) are strictly associated with the diabetes onset $^{45,46}$, while low iron levels improve the receptor sensitivity of insulin ${ }^{47}$.

High values of iron can promote the onset of cataracts $^{48}$ and a role of iron has been recognized in hepatic steatosis and in the nonalcoholic steatohepatitis (NASH) syndromes ${ }^{39}$, while high values of serum ferritin are correlated to metabolic syndrome which is in turn related to diabetes ${ }^{49-51}$. In 1981 J. Sullivan ${ }^{52}$ showed the cardiovascular protective action of a low level of body iron in women during the fertile era of menstrual cycle, and in 2005 the same author pointed out the relation between the quantity of iron in the deposit and the alteration of vascular reactivity ${ }^{53}$. The role of iperhomocysteinemia as vascular toxic factor is well recognized, while the observation that the mere supply of folates and of group B vitamins in presence of high values of ferritin is poorly effective in the regulation of the endothelial reactivity is less known ${ }^{54,55}$.

The relationships between iron and ischemic cardiac disease or the myocardial infarction have been reported in a number of papers in literature, and recently the correlation of high ferritin level and STEMI infarction (ST Elevation Myocardial Infarction) has been pointed out ${ }^{56-60}$. The ROS are surely involved in the cardiac insufficiency ${ }^{61,62}$. In fact, the xanthine-oxidase oxidizes the hypoxanthine to uric acid using oxygen as substrate and producing superoxide and peroxide anions $\left(\mathrm{O}_{2}{ }^{-\cdot}, \mathrm{H}_{2} \mathrm{O}_{2}\right)$, source of oxidative stress further enhanced in presence of unchelated iron and in condition of ischemia-perfusion ${ }^{3,4}$. 


\section{Endnotes}

[i] According to the International Union of Pure and Applied Chemistry (IUPAC) the point high on the right represents radicalic species.

\section{References}

1) Chance B, Sies $\mathrm{H}$ and Boveris A. Hydroperoxide metabolism in mammalian organs. Physiol Rev 1979, 59:527-605.

2) Fato R, Bergamini C, Leoni S, Strocchi $P$ and Lenaz G. Generation of reactive oxygen species by mitochondrial complex I: implications in neurodegeneration. Neurochem Res 2008,33:2487-501.

3) Bedard K and Krause KH. The NOX family of ROSgenerating NADPH oxidases: physiology and pathophysiology. Physiol Rev 2007, 87:245-313.

4) Brown JM, Terada LS, Grosso MA, Whitmann GJ, Velasco SE, Patt A, Harken AH and Repine JE. Xanthine oxidase produces hydrogenperoxide which contributes to reperfusion injury of ischemic, isolated, perfused rat hearts. J Clin Invest 1988,81:1297-1301.

5) Halliwell B and Gutteridge JM. Oxygen toxicity, oxygen radicals,transition metals and disease. Biochem J 1984, 219:1-14.

6) Halliwell B and Gutteridge JMC. Role of free radicals and catalytic metal ions in human disease - an overview. Meth Enzymol 1990, 186:1-85.

7) Galaris D and Pantopoulos K. Oxidative stress and iron homeostasis: mechanistic and health aspects. Crit Rev Clin Lab Sci 2008, 45:1-23.

8) Wardman P and Candeias LP. Fenton chemistry: An introduction. Rad Res 1996, 145:523-531.

9) Kehrer JP. The Haber-Weiss reaction and mechanisms of toxicity. Toxicology 2000, 149:43-50.

10) Fridovich I. Superoxide radical and superoxide dismutases.Annu Rev Biochem 1995, 64:97-112.

11) Minotti G. Sources and role of iron in lipid peroxidation. Chem Res Toxicol 1993, 6:134-146.

12) Evans MD, Dizdaroglu M and Cooke MS. Oxidative DNA damage and disease: induction, repair and significance. Mut Res 2004, 567:1-61.

13) Stadtman ER and Oliver CN. Metal-catalyzed oxidation of proteins - physiological consequences. J Biol Chem 1991, 266:2005-2008.

14) Davies MJ. The oxidative environment and protein damage. Biochim Biophys Acta 2005, 1703:93-109.

15) Jung $\mathrm{T}$, Bader $\mathrm{N}$ and Grune $\mathrm{T}$. Lipofuscin: formation, distribution, and metabolic consequences. Ann N Y Acad Sci 2007,1119:97-111.

16) Radi R, Cassina A, Hodara R, Quijano C and Castro L. Peroxynitrite reactions and formation in mitochondria. Free Radic Biol Med 2002, 33:1451-64.

17) Kim YM, Chung HT, Simmons RL and Billiar TR. Cellular nonheme iron content is a determinant of nitric oxide- mediated apoptosis, necrosis, and caspase inhibition. J Biol Chem 2000,275:10954-61

18) Stintzi A, Barnes C, Xu J and Raymond KN. Microbial iron transport via a siderophore shuttle: a membrane ion transport paradigm. Proc Natl Acad Sci USA 2000, 97:10691-6.

19) Braun V. Iron uptake mechanisms and their regulation in pathogenic bacteria. Int J Med Microbiol 2001, 291:67-79.

20) Ong ST, Ho JZS, Ho B and Ding JL. Iron-withholding strategy in innate immunity. Immunobiology 2006, 211:295-314.

21) Kaplan J. Mechanisms of cellular iron acquisition: another iron in the fire. Cell 2002, 111:603-6.

22) Ganz T. Hepcidin, a key regulator of iron metabolism and mediator of anemia of inflammation. Blood 2003, 102:783-788.

23) Flanagan JM, Truksa J, Peng HF, Lee $P$ and Beutler E. In vivo imaging of hepcidin promoter stimulation by iron and inflammation. Blood Cells Mols Dis 2007, 38:253-257.

24) Sullivan JL. Macrophage iron, hepcidin, and atherosclerotic plaque stability. Exp Biol Med (Maywood) 2007, 232:1014-20.

25) Trachtman H, Christen E, Cnaan A, Patrick J, Mai V, Mishra Jet al. Urinary neutrophil gelatinase associated lipocalcin in D+HUS: a novel marker of renal injury. Pediatric Nephrology 2006, 21:989-994.

26) Flower DR, North AC and Sansom CE. The lipocalin protein family: structural and sequence overview. Biochim Biophys Acta,2000, 1482:9-24.

27) Tschesche H, Zolzer V, Triebel S and Bartsch S. The human neutrophil lipocalin supports the allosteric activation of matrix metalloproteinases. Eur J Biochem 2001, 268:1918-1928.

28) Yan L, Borregaard N, Kjeldsen L and Moses MA. The high molecular weight urinary matrix metalloproteinase (MMP) activity is a complex of gelatinase B/MMP-9 and neutrophil gelatinase-associated lipocalin (NGAL). Modulation of MMP-9 activity by NGAL. J Biol Chem 2001, 276:37258-65.

29) Balla J, Vercellotti GM, Nath K, Yachie A, Nagy E, Eaton JW et al. Haem, haem oxygenase and ferritin in vascular endothelial cell injury. Nephrology Dialysis Transplantation 2003,18:8-12.

30) Poon HF, Calabrese V, Scapagnini G and Butterfield DA. Free radicals: key to brain aging and heme oxygenase as a cellular response to oxidative stress. J Gerontol A Biol Sci Med Sci 2004,59:478-93.

31) Vaziri ND and Rodriguez-Iturbe B. Mechanisms of disease: oxidative stress and inflammation in the pathogenesis of hypertension. Nat Clin Pract Nephrol 2006, 2:582-93.

32) Yakobson MG, Antonov AR, Golovatyuk AV, Efremov $\mathrm{AV}$, Markel AL and Yakobson GS. Iron content and parameters of blood antioxidant activity in rats with hereditary arterial hypertension during experimental myocardial infarction. Bull Exp Biol Med 2001,132:1041-4.

33) Peterson JR, Sharma RV and Davisson RL. Reactive oxygen species in the neuropathogenesis of hypertension. Curr Hypertens Rep 2006, 8:232-41.

34) Kim MK, Baek KH, Song KH, et al. Increased serum ferritin predicts the development of hypertension among middle-aged men. Am J Hypertens. 2012;25(4):492-7. 
35) Jehn ML, Guallar E, Clark JM, et al. A prospective study of plasma ferritin level and incident diabetes: the Atherosclerosis Risk in Communities (ARIC) Study. Am J Epidemiol 2007, 165:1047-54.

36) West IC. Radicals and oxidative stress in diabetes. Diabet Med 2000, 17:171-80.

37) Evans JL, Maddux BA and Goldfine ID. The molecular basis for oxidative stress-induced insulin resistance. Antioxid Redox Signal 2005, 7:1040-52.

38) Houstis N, Rosen ED and Lander ES. Reactive oxygen species have a causal role in multiple forms of insulin resistance. Nature 2006, 440:944-8.

39) Machado $M$ and Cortez-Pinto $H$. Nash, insulin resistance and iron. Liver International 2006, 26:1159-1162.

40) Chen X, Scholl TO and Stein TP. Association of elevated serum ferritin levels and the risk of gestational diabetes mellitus in pregnant women: The Camden study. Diabetes Care 2006, 29:1077-82.

41) Adams PC, Kertesz AE and Valberg LS. Clinical presentation of hemochromatosis: a changing scene. Am J Med 1991, 90:445-9.

42) Niedowicz DM and Daleke DL. The role of oxidative stress in diabetic complications. Cell Biochem Biophys 2005, 43.289-330.

43) Inoue I, Katayama S, Takahashi K,at al. Troglitazone has a scavenging effect on reactive oxygen species. Biochem Biophys Res Commun 1997,235:113-6.

44) Bao Y, Jia RH, Yuan J,et al.. Rosiglitazone ameliorates diabetic nephropathy by inhibiting ROS and its downstream-signaling pathways. Pharmacology 2007, 80:57-64.

45) Wang Y, Lam KSL, Kraegen EW et al Lipocalin-2 is an inflammatory marker closely associated with obesity, insulin resistance, and hyperglycemia in humans. Clinical Chemistry 2007, 53:34-41.

46) van Dam RM and Hu FB. Lipocalins and insulin resistance: Etiological role of retinol-binding protein 4 and lipocalin-2? Clinical Chemistry 2007, 53:5-7.

47) Fernández-Real JM, López-Bermejo A and Ricart W. Crosstalk between iron metabolism and diabetes. Diabetes 2002, 51:2348-54.

48) Allerson CR, Cazzola M and Rouault TA. Clinical severity and thermodynamic effects of iron-responsive element mutations in hereditary hyperferritinemia-cataract syndrome. Journal of Biological Chemistry 1999, 274:26439-26447.

49) Yudkin JS. Insulin resistance and the metabolic syndromeor the pitfalls of epidemiology. Diabetologia 2007, 50:1576-86.

50) Jehn M, Clark JM and Guallar E. Serum ferritin and risk of the metabolic syndrome in U.S. adults. Diabetes Care 2004, 27:2422-8.

51) Bozzini C, Girelli D, Olivieri O,et al. Prevalence of body iron excess in the metabolic syndrome. Diabetes Care 2005, 28:2061-3.

52) Sullivan JL. Iron and the sex difference in heart-disease risk. Lancet 1981, 1:1293-1294.

53) Sullivan JL. Stored iron and vascular reactivity. Arteriosclerosis Thrombosis and Vascular Biology 2005, 25:1532-1535.

54) Sullivan JL. Is homocysteine an iron-dependent cardiovascular risk factor? Kidney Int 2006, 69:642-4.

55) Clarke R. Homocysteine-lowering trials for prevention of heart disease and stroke. Semin Vasc Med 2005, 5:215-22.

56) Tuomainen TP, Punnonen K, Nyyssonen K and Salonen JT. Association between body iron stores and the risk of acute myocardial infarction in men. Circulation 1998, 97:1461-6.

57) Berenshtein E, Vaisman B, Goldberg-Langerman C et al. Roles of ferritin and iron in ischemic preconditioning of the heart. Mol Cell Biochem 2002,234:283-292.

58) Engberding N, Spiekermann S, Schaefer A, et al. Allopurinol attenuates left ventricular remodeling and dysfunction after experimental myocardial infarction: a new action for an old drug? Circulation 2004,110:2175-9.

59) Reyes AJ. Cardiovascular drugs and serum uric acid. Cardiovasc Drugs Ther 2003, 17:397-414.

60) Moradi M, Fariba F, Mohasseli AS, Relation between the serum ferritin level and the risk for acute myocardial infarction. J Res Health Sci. $2015 ; 15(3): 147-51$.

61) Engberding N, Spiekermann S, Schaefer Aet al.Allopurinol attenuates left ventricular remodeling and dysfunction after experimental myocardial infarction: a new action for an old drug? Circulation 2004,110:2175-9.

62) Reyes AJ. Cardiovascular drugs and serum uric acid. Cardiovasc Drugs Ther 2003, 17:397-414. 